DEVELOPMENT OF A CATALYTIC SYSTEM FOR GASIFICATION OF WET BIOMASS

D. C. Elliot

L. J. Sealock

M. R. Phelps

G. G. Neuenschwander

August - September 1993

Presented at the

First Biomass Conference of the Americas

August 30 - September 2, 1993

Burlington, Vermont

Work supported by

the U.S. Department of Energy

under Contract DE-AC06-76RLO 1830

Pacific Northwest Laboratory

Richland, Washington 99352

MASTER 


\title{
Development of a Catalytic System for Gasification of Wet Biomass
}

\author{
DC Elliott, L Sealock, MR Phelps, GG Neuenschwander, TR Hart \\ Pacific Northwest Laboratory, P.O. Box 999, MSIN K2-40 \\ Richland, Washington 99352
}

\begin{abstract}
A gasification system is under development at Pacific Northwest Laboratory that can be used with high-moisture biomass feedstocks. The system operates at $350^{\circ} \mathrm{C}$ and 205 atm using a liquid water phase as the processing medium. Since a pressurized system is used, the wet biomass can be fed as a slurry to the reactor without drying. Through the development of catalysts, a useful processing system has been produced.

This paper includes assessment of processing test results of different catalysts. Reactor system results including batch, bench-scale continious, and engineering-scale processing results are presented to demonstrate the applicability of this catalytic gasification system to biomass. The system has utility both for direct conversion of biomass to fuel gas or as a wastewater cleanup system for treatment of uncoverted biomass from bioconversion processes.

By the use of this system high conversions of biomass to fuel gas can be achieved. MediumBtu gas is the primary product. Potential exists for recovery/recycle of some of the unreacted inorganic components from the biomass in the aqueous byproduct stream.
\end{abstract}

\section{Introduction}

A pressurized catalytic gasification process, operated at low-temperature, is available under the trade name TEES ${ }^{\oplus}$ (Thermochemical Envirozmental Energy System, a registered trademark of Onsite* Ofsite, Inc., Duarte, California). It is effective for treating wet biomass streams to address both environmental cleanup and energy recovery goals. Through a liquid-phase, heterogeneously catalyzed process operated at nominally $350^{\circ} \mathrm{C}$ and 205 atm, TEES produces a methane/carbon dioxide product gas from water solutions or slurries of organics. This biomass gasification process was specifically developed for processing high-moisture biomasses (high-growth grasses, marine and aquatic biomass, 
and food processing residues), which are not efficiently gasified in conventicnal, low-pressure thermal systems (Elliott and Sealock 1985; Sealock et al. 1988). Later sudies applied the technology to the destruction of hazardous organic chemical wastes and organic chemical marufacturing wastewaters (Baker and Sealock 1988) as well as biomass feedstocks (Elliott et al. 1991).

Part of the continuing development of the TEES technology has involved studies on catalyst efficiency and integrity. Nickel catalysts have been used in the system throughout its development ind scaleup. This paper discusses experiments conducted and catalysts formulated for the purpose of maintaining high conversion and longer catalyst lifetimes in the subcritical, high-temperature, liquid-phase water operating environment of the TEES process. Many conventional catalysts developed for steam reforming, hydrogenation, and methanation, (the chemical mechanisms involved in TEES) have been evaluated. Many of these catalysts were found to be active for converting organics to methane and carbon aioxide but were not satisfactory for long-term operation. Experiments are described here which were used to evaluate a wide range of catalyst materials and support compositions.

In addition, this paper describes test results from the reactor systems which have been constructed to develop TEES for wet biomass applications. Most of our recent results are from continuous-flow reactor studies with a fixed bed of catalyst in a tubular reactor. These tests demonstrate the scale-up of a useful reactor configuration for industrial application of the TEES technology.

\section{BACKGROUND}

The use of high-pressure liquid water at elevated temperatures as a processing environment has recently been reviewed (Sealock et al. 1993). One application of this processing environment is for catalytic gasification of biomass. In this application, which we call TEES, catalysts accelerate the reaction of biomass with water and produce methane and carbon dioxide from the pyrolysis intermediates. TEES has been reported both as a means of recovering useful energy from wet biomass and other organics in water and as a water treatment system for more dilute hazardous organic contaminants. Batch reactor test results have demonstrated process applicability to a wide range of organic components (Sealock et al. 1988; Baker and Sealock 1988; Elliort et al 1993b). Development of catalysts for this processing environment has also been an important factor in making this processing technology viable (Elliott et al. 1993a).

TEES processing involves relatively complex chemistry including pyrolysis, steam-reforming, hydrogenation, methanation and water-gas shift. Specific chemistry varies with the feedstock type. For the biomass carbohydrate feedstocks used in the experiments described here, various reaction pathways are suggested by the products that have been identified:

$$
\begin{aligned}
& \mathrm{C}_{6} \mathrm{H}_{10} \mathrm{O}_{5}+\mathrm{H}_{2} \mathrm{O}->6 \mathrm{CO}+6 \mathrm{H}_{2} \\
& \mathrm{CO}+3 \mathrm{H}_{2}->\mathrm{CH}_{4}+\mathrm{H}_{2} \mathrm{O} \\
& \mathrm{CO}+\mathrm{H}_{2} \mathrm{O} \rightarrow>\mathrm{CO}_{2}+\mathrm{H}_{2}
\end{aligned}
$$

steam-reforming methanation water-gas shift

The .)verall stoichiometry approximates:

$$
\mathrm{C}_{6} \mathrm{H}_{10} \mathrm{O}_{5}+\mathrm{H}_{2} \mathrm{O}->3 \mathrm{CH}_{4}+3 \mathrm{CO}_{2}
$$

A thermodynamic equilibrium limitation of about $1 \%$ residual hydrogen (Sealock et al. 1988) shifts the methane/carbon dioxide product ratio slightly more toward the carbon dioxide than is suggested in the given stoichiometry. 
Early gasification tests in supercritical water showed no evidence of catalytic effects (Modell et al. 1981). Our past catalyst studies for the TEES concept have addressed contacting (mass transfer limitations) and the active form of the nickel catalyst (Butmer et al. 1987). Clear evidence was presented on the need for reduction of the nickel catalyst prior to processing (Baker and Sealock 1988). The reduced effectiveness of other Group VIII metals (compared to nickel), because of their oxidation (in high-temperature water) or lack of specific activity, was also reported (Baker and Sealock 1988). Evidence of the instability of conventional catalyst support materials when used at the reaction conditions was initially reported by Elliott et al. (1991). Continuous-flow reactor tests indicated that long-term stability of the nickel catalyst was a critical developmental requirement (Elliott et al. 1989; Baker et al. 1989a; Baker et al. 1989b, Elliott et al. 1991).

\section{Process Development}

Process development results can be conveniently separated into catalyst developmer: efforts and continuous reactor test results with biomass feedstocks.

\section{Catalyst Development}

The preliminary catalyst tests were performed in a batch reactor. These experiments tested the activity of the catalyst for the gasification and methanation of a model compound, para-cresol, and the long-term stability of the support in the high-pressure water reaction environment. Five groups of tests involving several different catalyst types or support materials are presented. The results of these tests are presented in Table1. The details of these tests are published elsewhere (Elliott et al. 1993a).

Table 1. Summary of Conclusions on TEES Catalysts and Catalyst Supports

Useful
Catalytic
Metals
$\mathrm{Ru}$
$\mathrm{Rh}$
$\mathrm{Ni}^{?}$

Inactive

Metals

$$
\begin{aligned}
& \text { Metals } \\
& \text { Oxidized } \\
& \text { at Conditions } \\
& \hline \mathrm{Co}^{2} \\
& \mathrm{Fe}^{2} \\
& \mathrm{Cr} \\
& \mathrm{Mo} \\
& \mathrm{W} \\
& \mathrm{Zn}
\end{aligned}
$$

$\begin{array}{lll}\text { Stable } & \text { Unstable } & \text { Hydroiyzable } \\ \text { Supports } & \text { Supports } & \text { Supports } \\ {_{2} \mathrm{O}_{3}} } & \mathrm{TiO}_{2} & \mathrm{y}-\mathrm{Al}_{2} \mathrm{O}_{3} \\ \mathrm{ZrO}_{2} & \mathrm{SiO}_{2} & \delta-\mathrm{Al}_{2} \mathrm{O}_{3} \\ \mathrm{C} & \mathrm{Ca} / \text { aluminate } & \eta-\mathrm{Al}_{2} \mathrm{O}_{3} \\ & \text { Kieselguhr } & \mathrm{SiO}_{2} / \mathrm{Al}_{2} \mathrm{O}_{3}{ }^{3}\end{array}$

subject to sintering

2 Baker et al. 1988

${ }^{3}$ Elliott et al. 1991 


\section{Base Metal Catalysis of TEES}

Various base metals and base metal combinations were tested as catalysts for TEES in the batch reactor system. The test results show that only the copper-zinc oxide catalyst exhibits any significant activity for the conversion of para-cresol or for methane formation. Essentially no activity is seen for all of the other catalysts despite the range of metal loading and physical properties of the catalysts tested. Most of the metals oxidized during the short batch test, as shown by $\mathrm{x}$-ray diffraction (XRD) analysis of the spent catalysts; only copper remained reduced at these reaction conditions.

\section{Innovative Nickel Catalysis of TEES}

Several different forms of nickel catalysts were tested in order to evaluate both their activity and their stability in the TEES operating environment. The forms included unsupported metal and solutions of nickel salts, neither of which were likely to be useful but both of which eliminated the need of a stable support. Only the conventional catalyst materials had significant catalyst activity. The nickel nitrate solution, which seems to show some activity, actually was serving as a reactant in that the nitrate oxidized a stoichiomtric amount of organic and then the reaction ceased. Nickel ion in solution appears to have no catalytic activity, as further supported by other tests with acetate (Elliott et al. 1993b). The different nickel metal forms, although highly divided, are just too limited in surface area to be useful as catalysts. The wire mesh had only about $0.0035 \mathrm{~m}^{2} / \mathrm{g}$ of surface area, while the nickel metal powder (assuming spherical particles) had only about $0.0045 \mathrm{~m}^{2} / \mathrm{g}$ of surface area. For comparison, the $\mathrm{Ni}-0750$ supported catalyst is reported to have $145 \mathrm{~m}^{2} / \mathrm{g}$ of surface area.

Sputtered-Ni on zirconia catalysts were nearly inactive. Loading of metal was limited to $<20 \mathrm{wt} \%$. Crystal-lite size was reasonable $(200-400 \AA$ ) implying a useful extent of $\mathrm{Ni}$ dispersion and surface area, but, apparently, the $\mathrm{Ni}$ was not well distributed in the sputtering process and the resulting surface area was low. Addition of the $\mathrm{Y}$ did not improve the dispersion as the activity was still nearly nonexistent.

Raney (Grace-Davison Specialty Chemical Company) nickel is an Al-Ni alloy with the Al leached away by strong caustic to leave a highly porous $\mathrm{Ni}$. The Raney nickel catalysts showed strong activity in the TEES environment both for gasification of organic and for methanation. Nearly all the para-cresol was removed from the water phase as indicated by the reduction of chemical oxygen demand (COD) of greater than $99 \%$ in both cases, as it was with the Ni-0750 catalyst. The Ni on alumina catalyst (Ni-0750) showed strong activity. The carbon deposition on the slurried catalyst was only slightly higher than the fresh catalyst.

\section{Conventionai Supported-Nickel Catalysts}

Numerous conventicnal supported nickel catalysts have been tested in TEES. The supported nickel catalysts exhibited a wide range of activities in the TEES environment, as shown by the results in Table 2. Table 2 includes data on the percentage of feed tock carbon converted to gas species (methane, carbon dioxide, ethane). The listed time is for minutes at temperature before the reaction was quenched. The Ni-0750 (a hydrogenation catalyst) and the two BASF catalysts, Cat A and Cat $\mathrm{B}$, (methanation catalysts) were the most active for gasification and methanation. The $\mathrm{Ni}-6220$ catalyst (a hydrogenation catayst) appeared to be neariy inactive. The PK-5 (a methanation catalyst) contains a lesser amount of nickel, $25 \%$, and was not completely reduced in this single batch test, based on hydrogen consumption calculations. Its low activity in the batch test confirms our earlier report of low activity in a continuous reactor test (Elliott et al. 1991). RKNR (a steam reforming 
catalyst) and C150, G49B, and C11-09-04 (methanation and steam reforming catalysts) have intermediate activities.

The spent catalysts from these tests were analyzed to determine if any significant changes had occurred. In addition, other samples of some of these catalysts were subjected to long-term batch tests in water. These samples were also analyzed to determine changes resulting from exposure to the high-pressure steam/water environment at $350^{\circ} \mathrm{C}$. Table 3 lists the components identified in the spent catalysts. XRD analysis of the spent catalysts proved that the nickel metal stayed reduced; however, there were significant changes noted in the composition of some of the support materials.

Table 2. Results of Tests with Various Supported Nickel Catalysts

\begin{tabular}{|c|c|c|c|c|c|c|}
\hline Catalyst & $\%$ Carbon & \multicolumn{3}{|c|}{ Product Gas, Vol\% } & Time, & Spent \\
\hline & Conversion & $\mathrm{CH}_{4}$ & $\mathrm{CO}_{2}$ & $\underline{\mathrm{H}}_{2}$ & $\min$ & Catalyst Form \\
\hline Ni-0750 R-S & 88.63 & 61.9 & 34.9 & 2.4 & 90 & $\mathrm{Ni}, \mathrm{AlOOH}$ (böhmite) \\
\hline BASF Cat A & 73.53 & 58.2 & 37.0 & 3.5 & 90 & $\mathrm{Ni}$, \\
\hline BASF Cat B & 68.62 & 60.8 & 34.5 & 3.7 & 90 & $\mathrm{Ni}$, \\
\hline C150 R-S & 54.21 & 57.9 & 36.1 & 4.1 & 100 & NA \\
\hline G49B R-S & 38.37 & 55.2 & 36.4 & 6.5 & 100 & NA \\
\hline RKNR R-S & 24.30 & 29.8 & 29.6 & 38.8 & 80 & NA \\
\hline C11-09-04 R-S & 5.24 & 15.2 & 32.5 & 50.3 & 100 & $\mathrm{Ni}, a$-alumina \\
\hline PK $-5(2 / 3$ reduced $)$ & 4.44 & 13.2 & 39.8 & 46.0 & 110 & $\mathrm{NiO}, \mathrm{Ni}, a-\&$-alumina \\
\hline $\mathrm{Ni}-6220 \mathrm{R}-\mathrm{S}$ & 0.82 & 3.1 & 24.2 & 70.4 & 75 & $\mathrm{Ni}$, amorphous support \\
\hline
\end{tabular}

$\mathrm{NA}=$ not available.

\section{Supported Noble Metal Catalysts}

Recently we have begun testing noble metal catalysts for TEES. Particularly interesting are Rh and $\mathrm{Ru}$ as these metals have been found by others to be useful methanation catalysts (Vannice 1975). Catalyst formulations with these metals typically contain much lower levels of metal because of their high cost. Ru and $\mathrm{Rh}$ catalysts demonstrated significant activity for the conversion of para-cresol to methane and carbon dioxide in the TEES processing system. The COD conversion was $>99 \%$ for the Ru on $\gamma$-alumina catalyzed test. Recent Pt and Pd test results confirm our earlier reports of the lack of activity in TEES of Pd (Elliott et al. 1991).

\section{Catalyst Support Evaluations}

Numerous types of catalyst support materials have been tested in the TEES environment. These materials were chosen from commercially available support materials. Extensive reaction with water has been discovered for most of these materials. All forms of alumina, except $\alpha$-alumina, react to form $\gamma-\mathrm{AlOOH}$, böhmite. The reaction of $\gamma$-alumina to böhmite results in a significant loss in physical integrity, as shown by the crush strength for Ni-0750 in Table 5 . The conversion of $\delta$ alumina to böhmite resulted in a dramatic loss in surface area from $147 \mathrm{~m}^{2} / \mathrm{g}$ to $15 \mathrm{~m} / \mathrm{g}$. The stability of the $\alpha$-alumina may also be tenuous since we are actually operating just outside the $\alpha$ alumina range (and in the böhmite range) in the phase diagram reported in the literature (Ervin and Osborn 1951). The monoclinic form of zirconia appears to be quite stable at these conditions, and tablets made of this material seem to maintain their integrity. Silica also is unreactive, but the 
dissolution of some of the material probably explains the destruction of the extruded pellets. Titania also appears to be unreactive at these conditions. One form of tableted titania, similar to the zirconia tablet, lost its physical strength after processing at TEES conditions. A carbon-supported ruthenium catalyst was evaluated for long-term stability in the batch reactor with only water present. Formation of small amounts of carbon dioxide and methane suggests that the ruthenium metal would catalyze the destruction of its support at a slow rate. Extrapolation of the gas production rate for 65 hours suggests a 542-day lifetime for the carbon granule.

\section{Continuous Reactor Tests}

Gasification tests were carried out in three scales of fixed-bed catalytic tubular reactor. The benchscale unit, shown schematically in Figure 1, was described in detail in an earlier report (Elliott et al. 1991). The unit consisted of a $6 \mathrm{ft}$ long $X 1$ in. I.D. 304SS tube which was fed from a cylindrical feed tank by a recipiccating plunger pump. The reactor was heated by an electrical resistance furnace and essentially served as both the preheater and the reactor. Pressure was controlled in the reactor by a dome-loaded, back-pressure regulator. The pressure regulator was followed by a condenser/separator system in which liquid samples were recovered. Uncondensed product gas was passed through flow meters and vented.

A microtubular version of this reactor system was used for catalyst lifetime studies. All the components shown in Figure 1 for the bench-scale unit were the same for the microtubular reactor system except for the pump and the reactor. A smaller reciprocating plunger pump was used to feed a reactor consisting of 12 in. of $1 / 2$ in. 316SS tubing. In addition to the reactor, there was a preheater section consisting of $7 \mathrm{ft}$ of $1 / 8 \mathrm{in}$. tubing. Both the reactor and the preheater were contained in the electrical resistance reactor furnace.

A scaled-up reactor system (SRS) was based on the bench-scale design. It was a transportable system designed at a scale of one-half ton per day of wet feed for obtaining engineering data for further scale-up of TEES. The SRS was mounted on a single $8 \mathrm{ft} \times 10 \mathrm{ft}$ skid platform that could be transported on a single flat-bed truck. Equipped with three $6 \mathrm{ft} X 2 \mathrm{in}$. I.D. fixed-bed tubular reactors and supporting equipment to achieve conversion, the test system's capacity was a one-half ton per day liquid feed with a design flow rate of $5 \mathrm{gal} / \mathrm{hr}$. Design working conditions for the reactors were $350^{\circ} \mathrm{C}$ at $238 \mathrm{~atm}$. This system is described in detail by Elliott et al. (1993c).

\section{Evaluation of Catalysts}

Several metal catalysts have been evaluated in the TEES continuous reactor systems. Based on catalyst screening in batch reactor tests, the focus of these evaluations was on the use of $\mathrm{Ni}$ and $\mathrm{Ru}$ as the catalytic metal. Catalyst support effects are also an important consideration, and several different support materials and unsupported Raney nickel catalyst were evaluated.

As shown by the results in Table 3, the long-term operation of Ni-0750 shows a definite loss of activity over time. The long-term loss of activity is apparent even when stable short-term activity has been demonstrated. The loss of activity is evident in the reduced level of COD destruction, lower gas yields, and shift in gas compositicn away from methane to hydrogen and higher hydrocarbons. The BASF catalyst shows much better long-term stability than the Ni-0750. Note that Table 3 is a combination of bench-scale results for the $\mathrm{Ni}-0750$ catalyst and microscale results for the BASF catalyst, so the gas yield results cannot be compared directly from one catalyst to the other. 
Table 3. Extended-Time Experimental Results with Nickel Catalysts

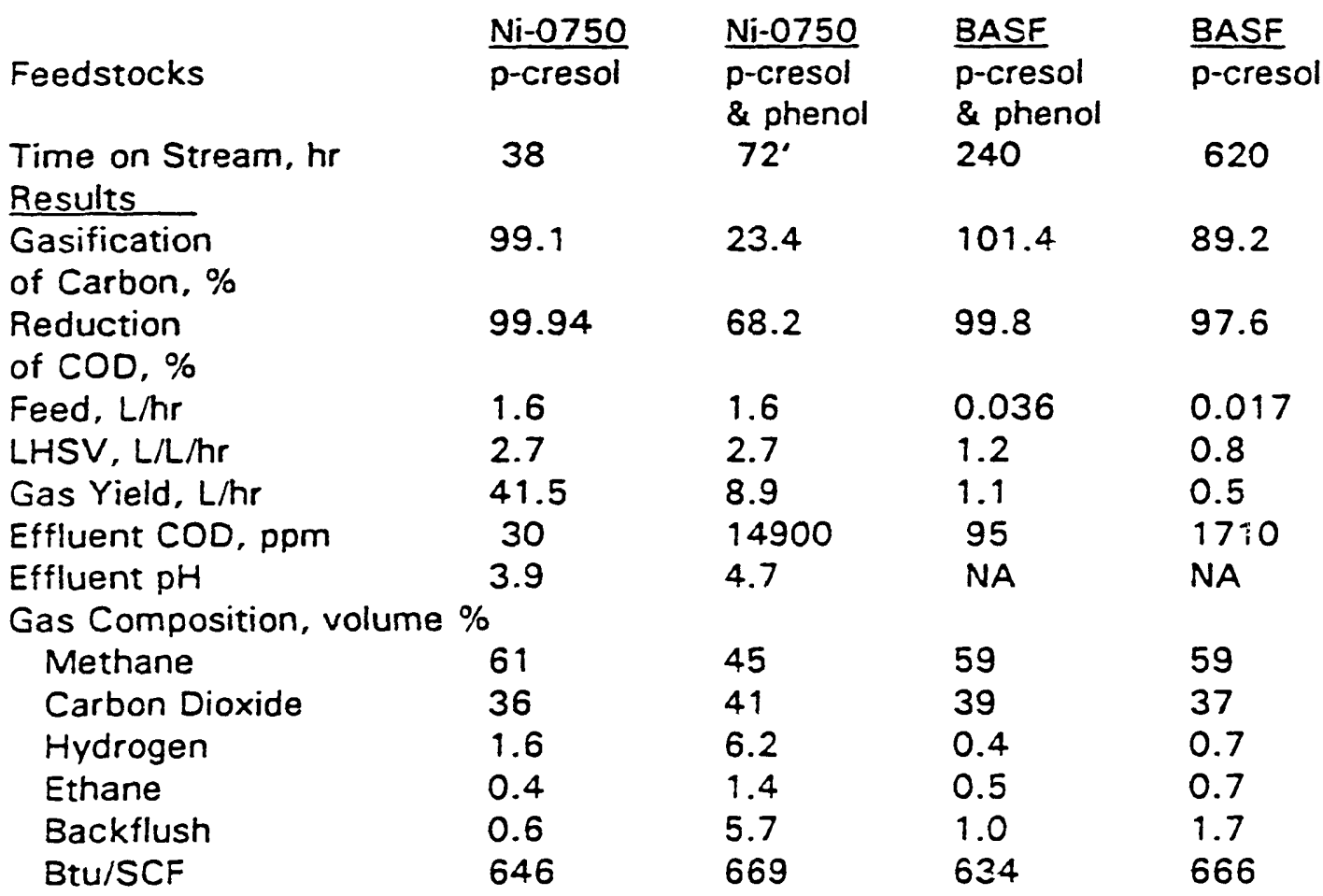

Catalyst bed conditions: $350^{\circ} \mathrm{C}$ to $369^{\circ} \mathrm{C}$ and 21 to $22 \mathrm{MPa}$.

Organic loading of $1.8 \mathrm{wt} \%$ in water as feedstock.

Metal agglomeration is a primary concern for catalysts used in TEES. Catalytic metal crystallite size has been correlated with the loss of active surface area and, hence, catalytic activity (Pearce and Patterson 1981). Figure 2 shows that different catalysts exhibit different rates and amounts of agglomeration. For example, the $\mathrm{Ni}-0750$ catalyst shows a nearly straight line growth in crystal size, while the BASF catalyst shows an initial growth of crystal size followed by a stable period which has been demonstrated for up to 4 weeks. The change in the Raney nickel is more nearly like the Ni0750 than the BASF catalyst. The data in Figure 2 are derived from tests in all three scales of continuous-feed reactor system. There is no significant difference in catalytic metal agglomeration that $r$ an be correlated to any of the scales of operation.

A different situation was found with $\mathrm{Ru}$. Ru showed no evidence of crystal growth. As seen in Figure 2, even a slight reduction in crystal size was apparent (although the change is just at the limit of the experimental error of the analysis). There was little evidence of an effect of the support on crystal growth. The Ru did not agglomerate when supported on the $\delta$-alumina (which is also readily converted to böhmite), as is shown in Figure 2. Analyses of the Ru on zirconia showed no sign of change as the $\mathrm{Ru}$ crystallite size remained much less than $10 \mathrm{~nm}$ for several samples recovered during 6 weeks of operation. Analysis of the zirconia support showed no significant growth of the crystallite size after the first 2 days of operation.

Table 4 provides results of long-term tests for comparison of two Ru catalysts. These tests showed good maintenance of conversion over time for both catalysts. COD destriction remained high with good gas yield. The alumina-supported catalyst showed significant loss of activity after 10 days of 
operation as evidenced by the lower space velocity required to maintain conversion levels. A shift away from methanation was noticeable toward the end of a 6-week test with the zirconia-supported $\mathrm{Ru}$, while the level of conversion remained high.

Table 4. Extended-Time Experimental Results with Ruthenium Catalysts

\begin{tabular}{|c|c|c|c|c|c|}
\hline $\begin{array}{l}\text { Feedstocks } \\
\text { Time on Stream, hr } \\
\text { Results }\end{array}$ & $\begin{array}{l}\frac{\mathrm{Ru} / \mathrm{Al}_{2}}{2} \mathrm{O}_{3} \\
\begin{array}{l}\mathrm{p} \text {-cresol } \\
80\end{array}\end{array}$ & $\begin{array}{l}\frac{\mathrm{Ru} / \mathrm{Al}_{2}}{\mathrm{O}_{3}} \mathrm{O}_{3} \\
\begin{array}{l}\text { p-cresol } \\
140\end{array}\end{array}$ & $\begin{array}{l}\frac{\mathrm{Ru} / \mathrm{Al}_{2}}{2} \mathrm{O}_{3} \\
\text { p-cresol } \\
230\end{array}$ & $\begin{array}{c}\frac{\mathrm{Ru} / \mathrm{ZrO}_{2}}{\text { phenol }} \\
432\end{array}$ & $\begin{array}{l}\frac{\mathrm{Ru} / \mathrm{ZrO}_{2}}{\text { phenol }} \\
864\end{array}$ \\
\hline $\begin{array}{l}\text { Gasification } \\
\text { of Carbon, \% }\end{array}$ & 95.4 & 90.6 & 97.6 & 100.2 & 83 \\
\hline $\begin{array}{l}\text { Reduction } \\
\text { of COD, \% }\end{array}$ & 98.5 & 96.6 & 99.4 & 99.4 & 95.6 \\
\hline Feed, L/hr & 2.0 & 1.3 & 1.2 & 0.038 & 0.036 \\
\hline LHSV, L/L/hr & 3.7 & 2.1 & 1.9 & 1.5 & 1.5 \\
\hline Gas Yield, L/hr & 46.3 & 27.7 & 29.1 & 1.1 & 0.85 \\
\hline Effluent COD, ppm & 718 & 1500 & 279 & 365 & 2300 \\
\hline Effluent $\mathrm{pH}$ & 3.8 & 3.6 & 3.9 & NA & NA \\
\hline \multicolumn{6}{|c|}{ Gas Composition, volume \% } \\
\hline Methane & 60 & 58 & 58 & 58 & 47 \\
\hline Carbon Dioxide & 36 & 38 & 38 & 38 & 45 \\
\hline Hydrogen & 1.6 & 1.6 & 1.2 & 1.6 & 2.7 \\
\hline Ethane & 1.2 & 1.5 & 1.2 & 1.2 & 1.7 \\
\hline Backflush & 1.6 & 1.9 & 1.3 & 1.5 & 3.4 \\
\hline Btu/SCF & 681 & 671 & 656 & 654 & 615 \\
\hline
\end{tabular}

Catalyst bed conditions: $350^{\circ} \mathrm{C}$ to $360^{\circ} \mathrm{C}$ and $21 \mathrm{MPa}$.

Organic loading of 1.8 to $2.0 \mathrm{wt} \%$ in water as feedstock.

\section{Bench-Scale Reactor Tests with Industrial Wastes}

Bench-scale reactor tests of TEES were also performed for biomass materials from commercial processes. These materials included olive wash water, delactosed cheese whey, and brewer's spent grain and spent grain liquor. As shown in Table 5, the test with the olive wash water had good results in terms of COD destruction. There was a significant ammonia product in the effluent water from nitrogen in the organic feed. Further treatment for ammonia removal may be required or incorporated into the process. One potential piocess modification for ammonia removal compatible with TEES is the reaction with stoichiometric amounts of nitric acid (Elliott et al. 1993b). The low gas recovery in these tests was probably as a result of carbonate formation with the ammonia. Alkali in the olive (and cheese whey) feedstock would also form carbonates at these conditions and further sequester carbon dioxide product gas.

In both of the cheese whey tests the result presented was only maintained for a limited time. Loss of catalyst activity occurred over a period of hours, apparently as a result of precipitation of alkali salts in the catalyst bed, coating the pellets and plugging the catalyst pores. Whitlockite, a calcium magnesium hydrogen phosphate $\left(\mathrm{Ca}_{18} \mathrm{Mg}_{2} \mathrm{H}_{2}\left(\mathrm{PO}_{4}\right)_{14}\right)$ has been identified by XRD of the deposits. The 
Table 5. Experimental Results with Industrial Waste Streams

\begin{tabular}{|c|c|c|c|}
\hline & $\begin{array}{l}\text { Olive } \\
\text { Wash } \\
\text { Water }\end{array}$ & $\begin{array}{l}\text { Cheese } \\
\text { Whey, } \\
\text { Delactosed }\end{array}$ & $\begin{array}{l}\text { Cheese } \\
\text { Whey, } \\
\text { Delactosed }\end{array}$ \\
\hline $\begin{array}{l}\text { Catalyst } \\
\text { Results }\end{array}$ & $\overline{\mathrm{Ni}-0750}$ & $\mathrm{Ni}-0750$ & $5 \% R u$ \\
\hline $\begin{array}{l}\text { Gasification } \\
\text { of Carbon, \% }\end{array}$ & 41.9 & 85.0 & 76.5 \\
\hline $\begin{array}{l}\text { Reduction } \\
\text { of COD. } \%\end{array}$ & 99.9 & 97.5 & 93.4 \\
\hline Feed, L/hr & 1.5 & 1.3 & 1.8 \\
\hline LHSV, L/L/hr & 2.5 & 2.3 & 3.4 \\
\hline Gas Yield, L/hr & 7.3 & 80.9 & 96.1 \\
\hline Effluent COD, ppm & 30 & 3700 & 8500 \\
\hline Effluent $\mathrm{NH}_{4}^{+}, \mathrm{ppm}$ & 350 & NA & NA \\
\hline Effluent $\mathrm{pH}$ & 6.9 & 7.0 & NA \\
\hline \multicolumn{4}{|c|}{ Gas Composition, volume \% } \\
\hline Methane & 62 & 48 & 48 \\
\hline Carbon Dioxide & 35 & 48 & 47 \\
\hline Hydrogen & 2.1 & 1.9 & 3.8 \\
\hline Ethane & 0.5 & 1.3 & 1.0 \\
\hline Backflush & 0.0 & 1.3 & 0.0 \\
\hline Btu/SCF & 649 & 555 & 515 \\
\hline
\end{tabular}

Catalyst bed conditions: $350^{\circ} \mathrm{C}$ and $21 \mathrm{MPa}$.

delactosed cheese whey is a much higher concentration feedstock thar tested in TEES in the past (Elliott et al. 1991). The delactosed feed was actually diluted 1:1 with water for these tests but 'vas still about twice as concentrated as in earlier tests. In addition, the delactosed feed would likely be less readily processed than whole cheese whey, as the more easily pyrolyzed components, the sugars, have been removed to a large degree, leaving the fats, proteins, and minerals. Long-chain hydrocarbons, as would be found in fats, have been shown to react more slowly in TEES (Elliott et al. 1993b). Therefore, the results reported in Table 5 are not quite as good as those reported earlier for conventional cheese whey.

Results from two tests with brewer's spent grain are provided in Table 6. The first test was done in the standard tubular reactor configuration. In this test, initial conversion was quite good, but a steady loss of activity was noted. After the test the catalyst bed was removed for analysis. The lower portion of the bed contained catalyst pellets coated with a brown material, which was analyzed by $\mathrm{XRD}$ and found to contain, as the principal crystalline phases, hydroxylapatite $\left[\mathrm{Ca}_{5}\left(\mathrm{PO}_{4}\right)_{3} \mathrm{OH}\right]$ and $\mathrm{Ni}_{3} \mathrm{~S}_{2}$. However, the nickel catalyst itself showed no unusual changes. Reuse of this catalyst bed (the 11-hr data set in Table 6) exhibited even poorer activity after handling. Regeneration of the bed was not attempted.

The second test used a reactor configuration incorporating a Carberry, stirred-tank catalytic reactor as a preheater in combination with the tubular, fixed-bed catalytic reactor. Similar results were obtained in this reactor configuration as with the tubular reactor alone. The use of the preneater to bring the feed to temperature more quickly and to increase the amount of the tubular catalyst bed at temperature did not appear to improve the conversion in the combined reactor system. Catalyst overload resulting 
from mass transfer limitations using the higher concentration feedstock in the combined reactor system may explain the poorer results at $4 \mathrm{hr}$ time on stream. Comparing the two data sets, there is an apparent feed rate effect of lower conversion at faster throughput, although the effect also correlates with time on stream. The higher levels of hydrogen in the product gas are a function of the higher temperature in the catalyst bed ( 360 s vs. 350 s in the tubular only test). There did not appear to be as quick a loss of activity in the catalyst bed as in the tubular reactor alone test.

Again, in the combined reactor system, the catalyst bed had a coating, this time after the 12 -hr test. In addition, there was a deposit recovered from the bottom of the Carberry reactor. The catalyst coating was similar to that found in the test with the tubular reactor only. The Carberry deposit consisted of the hydroxylapatite and the nickel subsulfide, but other phases were also identified by $X R D$, including iron phosphate, ammonium iron sulfate, potassium aluminosilicate, calcium carbonate, calcium magnesium sulfate and anorthoclase (an alkali silicoaluminate).

These tests show an improved operability compared with the earlier test results from the tubular reactor (Elliott et al. 1991). In the earlier tests with a less active catalyst, true steady-state conditions were not achieved. The carbon gasification was far lower than the COD conversion, suggesting that carbon was building up in the reactor system as unconverted material. T:e tests reported here have a good match between carbon gasification and COD conversion with the small difference probably resulting from soluble carbonates formed from the alkali and ammonia byproduct. The higher concentration feedstocks reported in Table 6 have COD loadings more representative of the industrial situation.

Table 6. Experimental Results with Brewer's Spent Grain

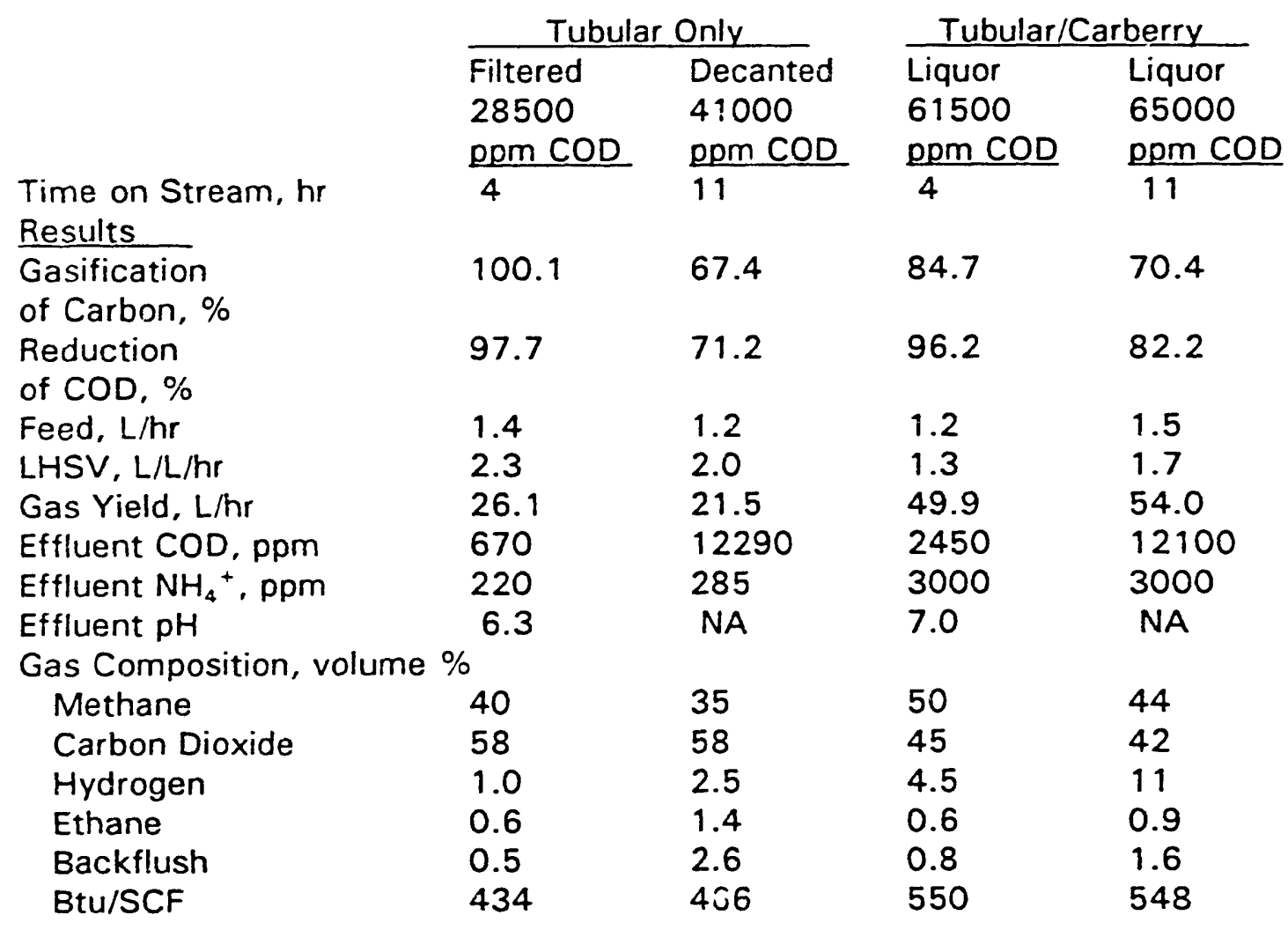

Catalyst bed conditions: BASF catalyst at $350^{\circ} \mathrm{C}$ to $360^{\circ} \mathrm{C}$ and $21 \mathrm{MPa}$. 


\section{Conclusions}

The TEES process has now been demonstrated in continuous-feed, fixed-bed catalytic reactor systems on three scales of operation ranging from $0.03 \mathrm{~L} / \mathrm{hr}$ to $33 \mathrm{~L} / \mathrm{hr}$. The systems have been operated with consistency at conditions of $350^{\circ} \mathrm{C}$ and $205 \mathrm{~atm}$. Aqueous effluents with low residual COD and a product gas of medium-Btu quality have been produced. Catalysts have been demonstrated for $i p$ to 6 weeks of operation with reasonable stability. Ruthenium appears to be a more stable catalyst than nickel in this respest. Biomass feedstocks have been processed effectively. Reduced nitrogen in these feedstocks is often converted into ammonia, which is stable at TEES conditions. Inorganic components in these feedstocks have sometimes been deposited in the catalyst bed when compounds were produced at concentrations above their solubility limits.

\section{Acknowledgments}

The authors acknowledge the support for this research provided by the U.S. Department of Energy through its Office of Industrial Technology and the program manager, Mr. Stuart Natof. Pacific Northwest Laboratory is operated for the U.S. Department of Energy by Battelle Memorial Institute under Contract DE-AC06-76RLO 1830. We gratefully acknowledge the catalyst samples received from BASF, United Catalysts, Haldor Topsoe. and Davison Chemical, and particularly the significant discussions and samples from Engelhard and Mr. Irvin Feins. The industrial participation of the Anheuser Busch Companies, Sheffield Products, and Oberti Olive Company, who provided samples of food processing wastes for testing, is also acknowledged. We have had assistance from several coworkers at PNL. Catalyst samples were produced for us by Larry Chick, Dean Matson, and Mark Buehler; Dave McCready did the XRD analyses. Finally, we acknowledge the support of our licensee, Onsite* Ofsite, Inc., in interacting with the industrial participants.

\section{References}

Baker, E. G.; Sealock, L. J., Jr. 1988. Catalytic Destruction of Hazardous Organics in Aqueous Solutions. PNL-6491-2, Pacific Northwest Laboratory: Richland, Washington.

Baker, E. G.; Butner, R. S.; Sealock, L. J., Jr.; Elliott, D. C.; Neuenschwander, G. G. 198 ta. Thermocatalytic Conversion of Food Processing Wastes: Topical Report FY 1988. PNL-6784, Facific Northwest Laboratory: Richland, Washington.

Baker, E. G.; Sealock, L. J., Jr.; Butner, R. S.; Elliott, D. C.; Neuenschwander, G. G.; Banns, N. G. 1989b. "Catalytic Destruction of Hazardous Organics in Aqueous Wastes: Continuous Reactor System Experiments." Hazardous Waste \& Hazardous Material, 6(1):87-94.

Butner, R. S.; Elliott, D. C.; Sealock, L. J., Jr. 1987. "Effect of Catalyst Type and Concentration on Thermal Gasification of High-Moisture Biomass Feedstocks." Biotechnol. and Bioeng., Symposium No. 17, John Wiley \& Sons, Inc.: New York, pp. 169-177.

Elliott, D. C.; Sealock, L. J., Jr. 1985. "Low Temperature Gasification of Biomass Under 
Pressure." In: Funiamenials of Thermochemical Biomass Conversion, R. P. Overend, T. A. Milne, and L. K. Mudge, eds.; Elsevier Applied Science Publishers: London, pp. 937-950.

Elliott, D.C.; Sealock, L. J., Jr.; Butner, R. S.; Baker, E. G.; Neuenschwander, G. G. 1989. LowTemperature Conversion of High-Moisture Biomass: Conitinuous Reactor System Results. PNL-7126, Pacific Northwest Laboratory: Richland, Washingtor.

Elliott, D. C.; Neuenschwander, G. G.; Baker, E. G.; Sealock, L. J., Jr.; Butner, R. S. 1991. Low-Temperature Catalytic Gasification of Wet Industrial Wastes, FY 1989-1990 Interim Report. PNL-7671, Pacific Northwest Laboratory: Richland, Washington.

Elliott, D.C.; Sealock, L. J., Jr.; Baker, E. G. 1993a. "Chemical Processing in High-Pressure Aqueous Environments. 2. Development of Catalysts for Gasification." accepted for publication in Ind. \& Eng. Chem. Res.

Elliott, D.C.; Sealock, L. J., Jr.; Baker, E. G. 1993b. "Chemical Processing in High-Pressure Aqueous Environments. 3. Evaluation of Feedstock Effects." submitted for publication; PNL-SA22103, Pacific Northwest Laboratory, Richland, Washington.

Elliott, D.C.; Phelps, M. R.; Sealock, L. J., Jr.; Baker, E. G. 1993c. "Chemical Processing in High-Pressure Aqueous Environments. 4. Results from Continuous-Feed Reactor Systems." submitted for publication; PNL-SA-22389, Pacific Northwest Laboratory, Richland, Washington.

Ervin, G., Jr.; Osborn, E. F. 1951. "The System $\mathrm{Al}_{2} \mathrm{O}_{3}-\mathrm{H}_{2} \mathrm{O}$." J. of Geol., 59: 381-394.

Modell, M.: Reid, R. C.; Amin, S. 1978. Gasification Process. U. S. Patent 4,113,446. Sept. 12.

Pearce, R.; Patterson, W. R. 1981. Catalysis and Chemical Processes. John Wiley \& Sons, Inc.: New Yoik, p.15.

Sealock, L. J., Jr.; Elliott, D. C.; Butner, R. S.; Neuenschwander, G. G. 1988. Low-Temperature Conversion of High-Moisture Biomass: Topical Report January 1984 - January 1988. PNL-6726, Pacific Northwest Laboratory: Richland, Washington.

Sealock, L. J., Jr.; Elliott, D.C.; Baker, E. G.; Butner, R. S. 1993. "Chemical Processing in HighPressure Aqueous Environments. 1. Historical Perspective and Continuing Developments." accepted for publication in Ind. \& Eng. Chem. Res.

Vannice, M. A. 1975. "The Catalytic Synthesis of Hydrocarbons from $\mathrm{H}_{2} / \mathrm{CO}$ Mixtures over the Group VIII Metals: 1. The Specific Activities and Product Distributions of Supported Metals." J. of Catalysis, 37: 449-461. 


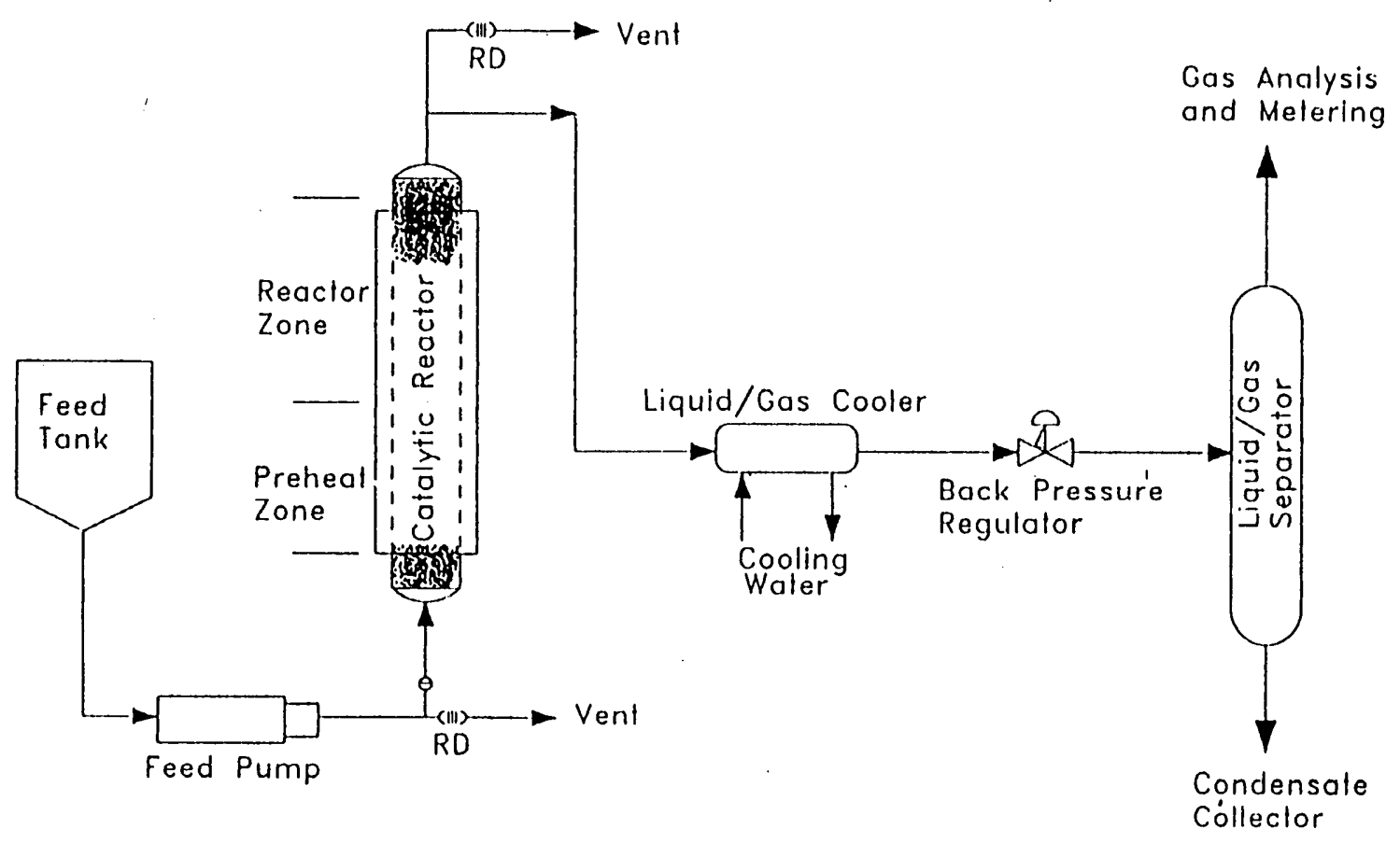

Figure 1. Schematic of Bench-Scale Continuous Reactor System 


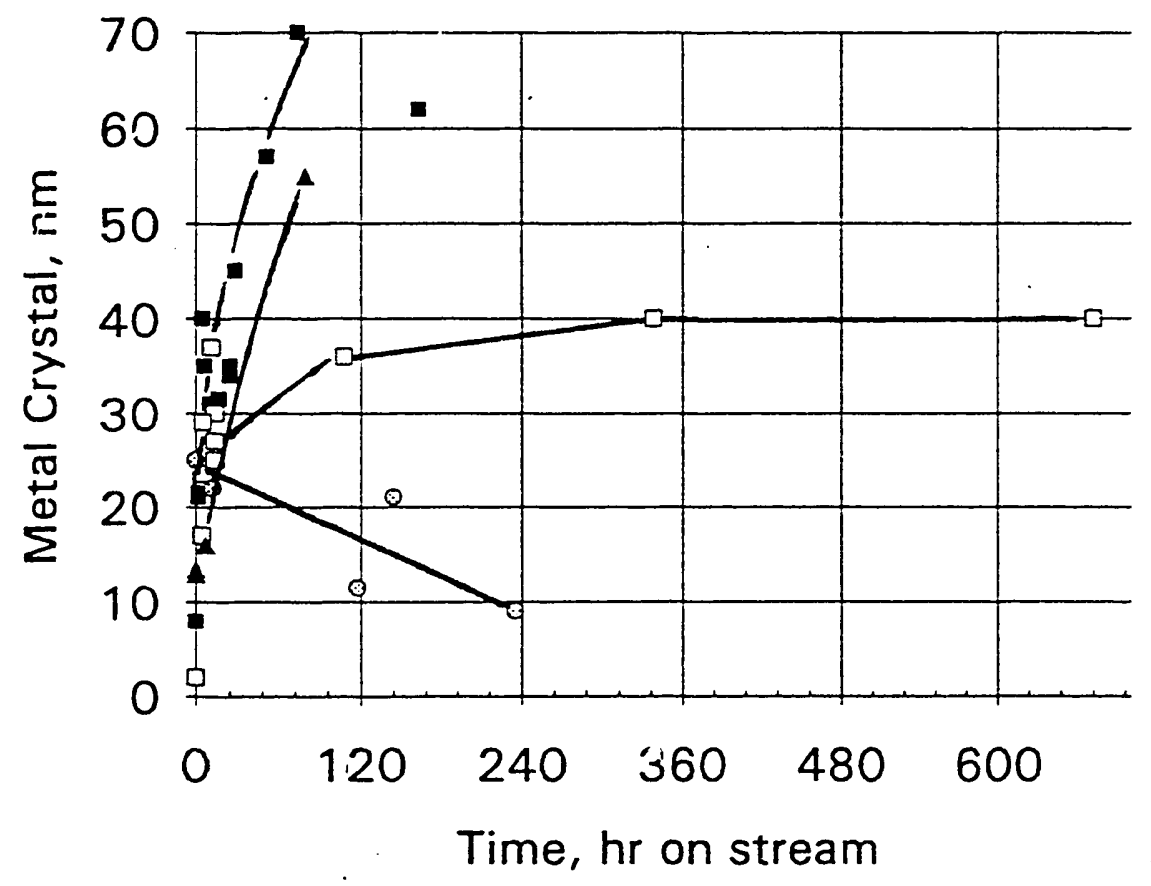

- Ni-0750

$\square$ BASF

- Raney Nickel

- Ru/AI203

Figure 2. Effect of Operating Time on Catalytic Metal Crystallite Size 

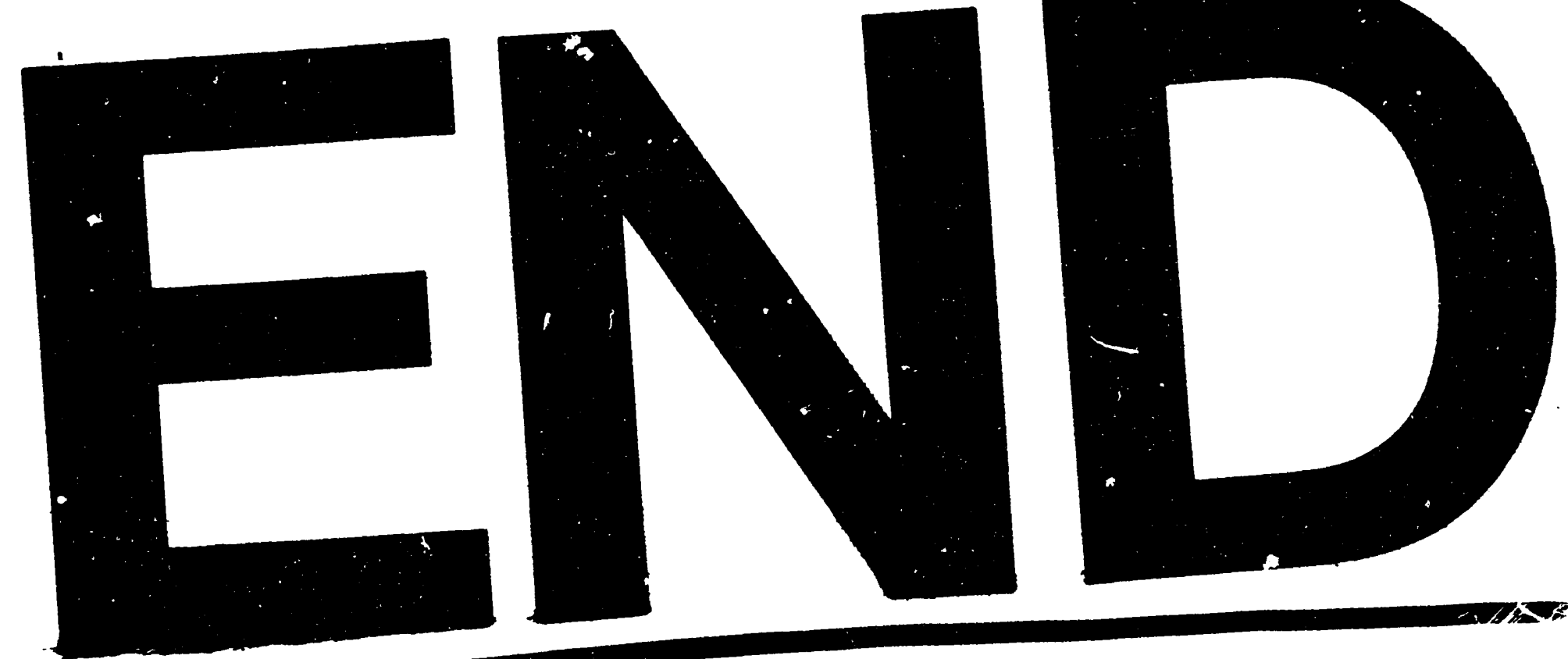

- 2040
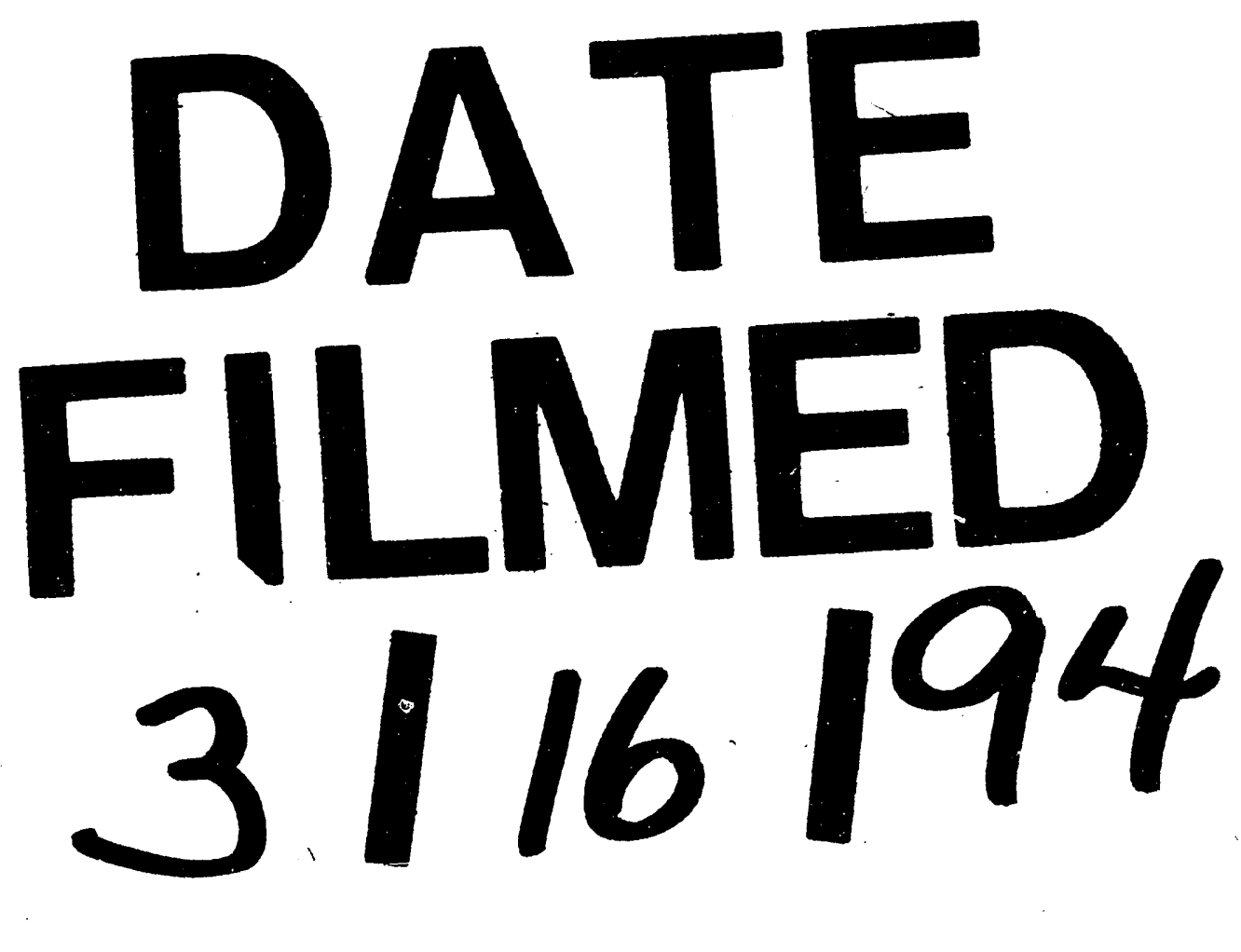